\title{
Intraglomerular Pressure and Mesangial Stretching Stimulate Extracellular Matrix Formation in the Rat
}

\author{
Bruce L. Riser, * Pedro Cortes, * Xiyuan Zhao, * Jay Bernstein, ${ }^{*}$ Francis Dumler, * and Robert G. Narins * \\ With the technical assistance of Clare C. Hassett, K. S. Sury Sastry, James Atherton, and M. Ann Holcomb \\ * Department of Internal Medicine, Division of Nephrology and Hypertension, Henry Ford Hospital, Detroit, Michigan 48202, \\ and ${ }^{\ddagger}$ Research Institute and Department of Anatomic Pathology, William Beaumont Hospital, Royal Oak, Michigan 48073
}

\begin{abstract}
To define the interplay of glomerular hypertension and hypertrophy with mesangial extracellular matrix (ECM) deposition, we examined the effects of glomerular capillary distention and mesangial cell stretching on ECM synthesis. The volume of microdissected rat glomeruli $\left(V_{z}\right)$, perfused ex vivo at increasing flows, was quantified and related to the proximal intraglomerular pressure (PIP). Glomerular compliance, expressed as the slope of the positive linear relationship between PIP and $V_{2}$ was $7.68 \times 10^{3} \mu^{3} / \mathrm{mmHg}^{3}$. Total $V_{g}$ increment (PIP 0-150 $\mathrm{mmHg})$ was $1.162 \times 10^{6} \mu \mathrm{m}^{3}$ or $61 \%(n=13)$. A $16 \%$ increase in $\mathrm{V}_{\mathrm{g}}$ was obtained over the PIP range equivalent to the pathophysiologial limits of mean transcapillary pressure difference. A similar effect of renal perfusion on $\mathrm{V}_{\boldsymbol{z}}$ was also noted histologically in tissue from kidneys perfused/fixed in vivo. Cultured mesangial cells undergoing cyclic stretching increased their synthesis of protein, total collagen, and key components of ECM (collagen IV, collagen I, laminin, fibronectin). Synthetic rates were stimulated by cell growth and the degree of stretching. These results suggest that capillary expansion and stretching of mesangial cells by glomerular hypertension provokes increased ECM production which is accentuated by cell growth and glomerular hypertrophy. Mesangial expansion and glomerulosclerosis might result from this interplay of mechanical and metabolic forces. (J. Clin. Invest. 1992. 90:19321943.) Key words: glomerulus • glomerulosclerosis • mesangium • hypertension • matrix

\section{Introduction}

Progressive glomerulosclerosis in rats with remnant kidneys or diabetes mellitus correlates more closely with associated glomerular hypertension than with concomitant increments in filtration rate and plasma flow (1-4). The mechanism whereby increased glomerular capillary pressure may lead to glomerular

Portions of the material in this manuscript were presented at the meetings of the American Society of Nephrology, 17-20 November 1990, Baltimore, MD; the International Congress of Nephrology, 15-20 July 1990, Tokyo, Japan; and the Federation of American Societies for Experimental Biology, 1-5 April 1990, Washington, DC.

Address correspondence to Dr. Pedro Cortes, Division of Nephrology and Hypertension CFP-5, Henry Ford Hospital, 2799 West Grand Boulevard, Detroit, MI 48202.

Received for publication 13 February 1992 and in revised form 20 May 1992.

J. Clin. Invest.

(c) The American Society for Clinical Investigation, Inc.

$0021-9738 / 92 / 11 / 1932 / 12 \$ 2.00$

Volume 90, November 1992, 1932-1943 damage from accumulated basement membrane-like material is presently unknown. Proposed pathogenetic factors include increased mesangial traffic and trapping of macromolecules (5) and direct mechanical disruption of the capillary wall (4).

Glomerular hypertrophy, a frequent concomitant of increased intracapillary pressure, has also been proposed as the predominant factor in the development of glomerular injury (6). Under specific experimental conditions, the pernicious effects of glomerular hypertrophy have been separated from those of hypertension, demonstrating that the former may independently cause glomerulosclerosis $(6-10)$. Overactivity of growth-promoting factors which stimulate extracellular matrix (ECM $)^{1}$ production may serve to link glomerular hypertrophy with subsequent sclerosis (11-13). Glomerular enlargement also increases glomerular wall tension and the detachment of epithelial cells from the capillary basement membrane. This effect is independent of intraglomerular pressure changes and may also mediate glomerular damage $(7,14)$. Recent evidence indicates that, while increased glomerular capillary pressure and glomerular hypertrophy may exert independent effects, they also act synergistically, causing glomerular injury and accelerated sclerosis (15).

We reasoned that expansion of glomerular capillaries and stretching of the mesangium occurring in response to hypertension might serve as the proximate force that translates high pressure into increased ECM formation. Accordingly, we first defined the relationship between induced changes in glomerular capillary pressure and glomerular volume. We then determined ECM production by cultured mesangial cells with different rates of cell growth and whether this production responds to mechanical stretch. The results do, indeed, suggest that capillary expansion and mesangial stretching stimulate ECM formation.

\section{Methods}

Materials. The purified ECM components used as standards included rat collagen type I (Upstate Biotechnology, Inc., Lake Placid, NY), murine collagen type IV, murine laminin (both from Collaborative Research, Bedford, MA), and rat fibronectin (Chemicon International, Inc., Temecula, CA ). The antibodies used were polyclonal antirat collagen type I, anti-rat fibronectin (both from Chemicon International), anti-mouse collagen type IV, and anti-murine laminin (both from Collaborative Research). All tissue culture media and perfusion solutions were based on an RPMI 1640 medium buffered with $25 \mathrm{mM}$ Hepes (380-2400; Gibco Laboratories, Grand Island, NY). Proline $\mathrm{L}-\left[{ }^{14} \mathrm{C}(\mathrm{U})\right], 286 \mathrm{mCi} / \mathrm{mmol}$; proline $\mathrm{L}-\left[2,3,4,5,-{ }^{3} \mathrm{H}\right], 112 \mathrm{Ci} / \mathrm{mmol}$; hydroxyproline $\mathrm{L}-4-\left[{ }^{3} \mathrm{H}(\mathrm{G})\right], 5.5 \mathrm{Ci} / \mathrm{mmol}$; inulin $\left[{ }^{3} \mathrm{H}(\mathrm{G})\right], 257$

1. Abbreviations used in this paper: ECM, extracellular matrix; PIP, proximal intraglomerular pressure; $\mathrm{V}_{\mathbf{0}}$, volume of the nonperfused glomerulus. 
$\mathrm{mCi} / \mathrm{g}$ were all purchased from New England Nuclear Research Products (DuPont Co., Wilmington, DE). The purity of the radioisotopic internal standards was established before their use by chromatographic analysis (see below). Additives to tissue culture media were cell culture-tested quality (Sigma Chemical Co., St. Louis, MO). Specifications for the columns used for HPLC were $4.6 \mathrm{~mm} \times 25 \mathrm{~cm}$ Ultrasphere ODS, 5- $\mu \mathrm{m}$ particle size (Beckman Instruments Inc., San Ramon, CA).

Glomerular microperfusion. Male Fischer CDF॰ (F-344)/CrlBR rats weighing 280-360 g were anesthetized with an ether $/ \mathrm{O}_{2}$ mixture. The aorta above the renal arteries was occluded and retrograde perfusion of the kidneys was carried out via a 22-gauge needle placed in the abdominal aorta at a point between its bifurcation and the renal arteries. The perfusion solution, RPMI 1640 medium, was modified to contain the following: $5 \mathrm{mM} d$-glucose, $20 \mu \mathrm{M}$ sodium orotate, $2 \mathrm{mM}$ glycine, $0.5 \mathrm{mM}$ reduced glutathione, $4 \mathrm{~g} / \mathrm{dl} \mathrm{BSA}, 100 \mathrm{U} / \mathrm{ml}$ penicillin, $100 \mu \mathrm{g} / \mathrm{ml}$ streptomycin, and $1 \%$ of ITS + premix (Collaborative Research) (providing per milliliter, $6.25 \mu \mathrm{g}$ selenious acid, $5.35 \mu \mathrm{g}$ linoleic acid, $6.25 \mu \mathrm{g}$ insulin). Before use, the perfusion solution was filtered through a $0.22-\mu \mathrm{m}$ filter, equilibrated in a hollow fiber oxigenator (Cell-Pharm; CD Medical, Inc., The Dow Chemical Co., Miami Lakes, FL) with $5 \% \mathrm{CO}_{2} / 95 \% \mathrm{O}_{2}$ at $37^{\circ} \mathrm{C}$, and its $\mathrm{pH}$ adjusted to 7.40 with $1 \mathrm{~N} \mathrm{NaOH}$. Perfusions were carried out with perfusate at $4^{\circ} \mathrm{C}$ for 2 min at $120 \mathrm{mmHg}$ (measured at the tip of the perfusion needle) while ice-cold $0.15 \mathrm{M} \mathrm{NaCl}$ was poured over the left kidney. At the end of the perfusion period, $4 \mathrm{ml}$ of a 6-7 g/ $\mathrm{dl}$ of dye-complexed BSA dissolved in perfusate solution was infused at the same pressure. This dye-BSA complex, prepared by consecutive binding to Coomassie blue and Evans blue, was used to facilitate arteriolar and glomerular tuft visualization during tissue microdissection.

Outer cortical glomeruli, with or without Bowman's capsule, but retaining their afferent arterioles, were dissected from tissue slices taken from the left kidney. Slices were immersed in the same $4^{\circ} \mathrm{C}$ perfusion solution as noted above. Dissections were done using a stereo microscope (SZH; Olympus Co., Overland Park, KS) and sharpened titanium forceps. To avoid possible effects of vasoconstriction and to facilitate the intraglomerular transmission of pressure, afferent arterioles were cut short. Compliance measurements were carried out in one glomerulus per animal using microperfusion techniques previously described by Osgood et al. (16). After transferring the dissected glomerulus to a $0.55-\mathrm{ml}$ temperature-regulated observation chamber mounted on an inverted microscope (Diaphot; Nikon Inc., Garden City, NY) and containing the same solution used for perfusion, the afferent arteriole was drawn into a holding pipette and cannulated with a matching perfusion pipette while the temperature was maintained at $4^{\circ} \mathrm{C}$. After cannulation, a $2-\mu \mathrm{m}$ outer diameter pipette filled with a $7 \mathrm{~g} / \mathrm{dl}$ solution of FD\&C green was advanced into the afferent arteriole through the opening of the perfusion pipette, its tip being placed at a point close to the mesangial region (Fig. 1) for the direct measurement of hydrostatic pressure (proximal intraglomerular pressure, PIP) by the Landis technique (16). With this technique, the flow of dye is observed at the tip of the pressure pipette while various pressures are applied to its contents using a pneumatic transducer tester (model DPM-IB; Bio-Tek Instruments Inc., Winooski, VT); the pressure at which there is no flow of dye into the afferent arteriole or perfusion fluid into the pressure pipette, is considered the pressure at the pipette's tip. The time between killing the animal and full glomerular cannulation varied from 50 to 90 min. After the correct positioning of the pipettes was confirmed by injection of dye, the chamber temperature was increased to $37^{\circ} \mathrm{C}$. After a 10-min initial incubation period, compliance measurements were begun. All experiments were carried out using the above described perfusion solution as both incubation medium and perfusate.

The initial volume of the nonperfused suspended glomerulus $\left(V_{0}\right)$ and its changes during perfusion were examined by a high resolution 3-CCD video camera (DXC-750; Sony Corp. of America, Park Ridge, NJ) and monitor (PVM-1343MD; Sony) with continuous recording of the image using an extended definition digital video recorder (Betamax EDV-7500; Sony). The recorded images were quantitatively evaluated

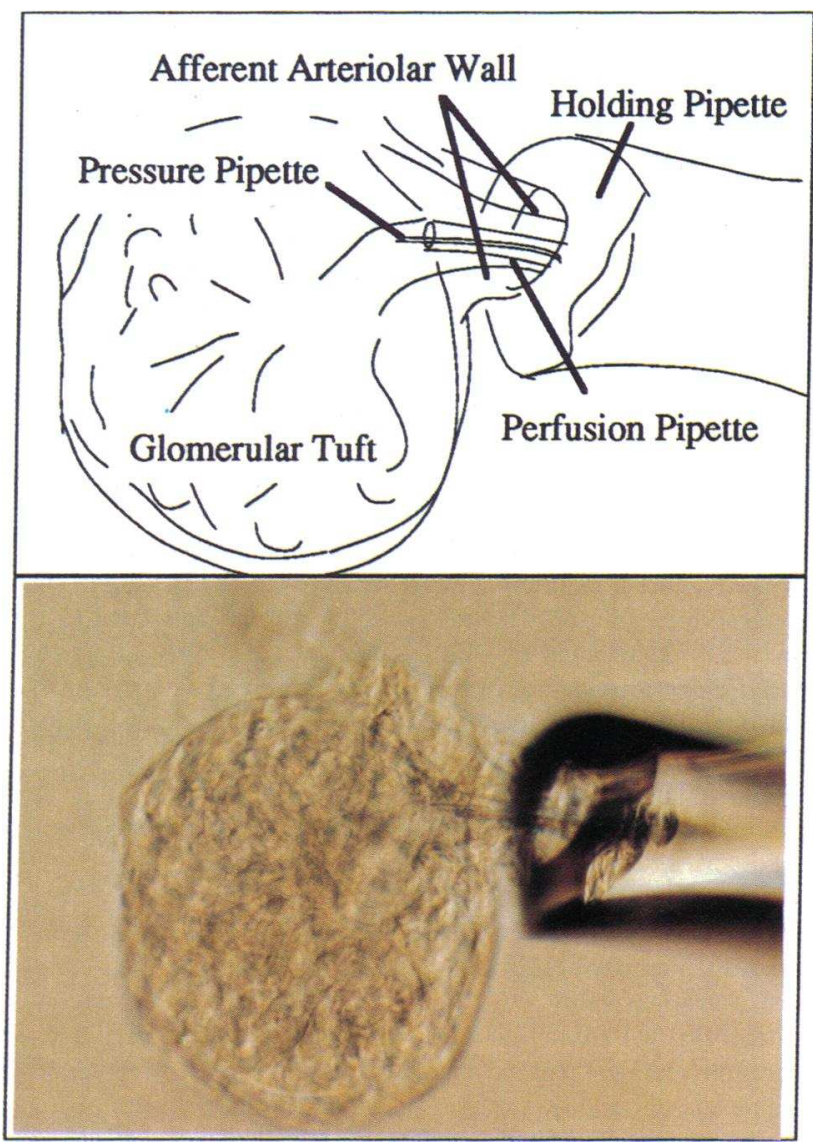

Figure 1. Detail of the positioning of the perfusion and pressuremeasuring pipettes within the glomerulus for the measurement of proximal intraglomerular pressure during changes in perfusion flow rate. A glomerulus, with Bowman's capsule attached, is shown while being perfused at $60 \mathrm{mmHg}$. $\times 230$.

using an image analysis system (Image-1; Universal Imaging Co., West Chester, PA). At each intraglomerular pressure, the image corresponding to the focusing plane that provided the largest glomerular perimeter, was enhanced by background subtraction and edge sharpening to obtain clear outlines, and used for quantitative analysis at a magnification of 760. A computer-assisted best fit of the ellipse encompassing the glomerular perimeter was used for volume estimation. Volume was calculated according to the magnitude of the planar maximal and minimal axes, assuming the glomerulus to be a symmetrical ellipsoid rotated over its longest axis. Glomerular volume was measured at zero pressure and separately at 6-18 different intraglomerular pressures, obtained by the stepwise increase in perfusate flow, between 0 and 200 $\mathrm{mmHg}$. Measurements were then repeated as pressure was reduced in a similar stepwise fashion. Finally, $\mathrm{V}_{0}$ was measured again to demonstrate complete return to initial volume, thus identifying possible unrecoverable deformation caused by structural damage. Failure to return to initial $\mathrm{V}_{0}$ only occurred at pressures above $150 \mathrm{mmHg}$. In three glomeruli in which full return to initial $\mathrm{V}_{0}$ was not achieved, volume values for pressures above $150 \mathrm{mmHg}$ and those obtained during the subsequent lowering in pressure were excluded from analyses. Active filtration, demonstrated by the injection of dye, was evident in all perfused glomeruli. The time required for all measurements was 45-60 min.

Histological study of glomerular morphology. Right kidneys of anesthetized Fischer rats, weighing 175-230 g, were removed after ligature of the renal pedicle, immediately placed in cold PBS, and 1-mm cortical slices fixed by immersion in isotonic sodium cacodylate buffer, $\mathrm{pH}$ 7.4 containing $4 \% p$-formaldehyde. Left kidneys were perfused at con- 
trolled pressure for a period of 3 min with sodium cacodylate buffer at $37^{\circ} \mathrm{C}$ using a method similar to that described above. This was followed by in situ fixation of the tissue by perfusion at the same pressure with $4 \% p$-formaldehyde in the same buffer solution for $2 \mathrm{~min}$. Glomerular volume and peripheral glomerular basement membrane (GBM) thickness were quantified by light and electron microscopic examination in transverse slices taken from the center of the kidneys fixed by perfusion and in the immersion-fixed samples from the contralateral kidneys. To this end, separate sections were processed as follows: $(a)$ for light microscopy, dehydrated in graded ethanol and embedded in paraffin for staining with periodic acid-Schiff; $(b)$ for electron microscopy, postfixed in osmium tetroxide, dehydrated, and embedded in LX-122 epoxy resin and sections stained with uranyl acetate/lead citrate. Glomerular volume was measured in 95 magnification photomicrographs obtained from the tissue processed into paraffin using a Videoplan (Carl Zeiss Inc., Thornwood, NY). The thickness of the peripheral glomerular basement membrane was determined in 16,000 magnification electronmicrographs by the method of orthogonal intercepts (17) in which the actual mean of width is calculated from its harmonic mean. Since previous studies in similar rats demonstrated substantial changes in glomerular volume with age (18), results obtained in the perfused left kidney were compared to those in the nonperfused right kidney from the same animal.

Mesangial cells. Cultured cells consisted of a cloned line isolated from glomerular mesangial outgrowths, obtained from male Fisher rats, which were characterized as described previously (19). In brief, mesangial cells were characterized on the basis of: $(a)$ fusiform appearance and the presence of intracellular fibrils as identified by transmission electron microscopy; $(b)$ ability to grow in medium containing $d$-valine; $(c)$ growth inhibition when cultured in the presence of heparin or mitomycin; $(d)$ marked increase in guanosine 5'-cyclic monophosphate content upon exposure to atrial natriuretic peptide ( 11 -fold greater than control 3T3 fibroblasts); $(e)$ presence of dense cytoplasmic immunochemical staining for type IV collagen, fibronectin, and laminin. In addition, prolonged growth of these cells at confluency resulted in the appearance of "cell hillocks" containing abundant amounts of ECM material (20). These cells have retained their mesangial cell characteristics, including typical morphology and ECM profiles, upon repeated passaging.

Application of mechanical strain to cultured cells. Mesangial cells were seeded $\left(2.1\right.$ to $17.0 \times 10^{4}$ cells $/ 25-\mathrm{mm}$ diameter well $)$ into sixwell plates with flexible elastin-coated bottoms (Flex I plates; Flexercell, McKeesport, PA) and cultured in $1 \mathrm{ml} /$ well of growth medium. This medium was RPMI 1640 containing penicillin, streptomycin, and $20 \% \mathrm{Nu}-$ Serum (Collaborative Research). In addition, $20 \mathrm{mM}$ glucose was added to enhance ECM production ( 21 ). $18 \mathrm{~h}-5 \mathrm{~d}$ later, one half of the plates were subjected to a 1- to 7-d period of cyclic stretching (experimental group) and the remaining plates were maintained in a static environment under identical conditions (control group). Mechanical strain was achieved by controlled vacuum/pressure cycles applied to the underside of the flexible-bottom culture well using a computer-assisted system (Strain Unit ${ }^{\star}$; Flexercell). This system provides precisely timed, negative pressure cycles of controlled magnitude, deforming the bottom of the culture well and stretching the cells attached to its surface. As the negative pressure is applied the membrane deforms hemispherically downward from its flat position at rest, producing a region of maximal stretch in the outer annulus of the well (principally uniaxial strain along a radius) with a geometric decrease of strain towards zero at the center of the membrane. All experiments were carried out using alternating cycles of $10 \mathrm{~s}$ stretch and $10 \mathrm{~s}$ relaxation at a rate of three cycles $/ \mathrm{min}$. Vacuum intensity was set to provide maximum elongation of $19 \%$ (outer annulus), equivalent to an average elongation of $\sim 7 \%$ over the entire culture plate surface.

Measurement of total collagen synthesis. When the rate of total collagen synthesis was to be measured, the culture medium was changed $24 \mathrm{~h}$ before the start of the radiolabeling period to an experimental medium, the composition of which was similar to that of the growth medium, but contained $0.6 \mathrm{mM} \beta$-aminopropionitrile, $0.2 \mathrm{mM}$ ascorbic acid, and lacked proline (except for that contained in NuSerum which yielded a final proline concentration of $40 \mu \mathrm{M}$ ). After collecting plates for baseline values, radiolabeling was carried out by incubation of separate groups of plates for 24,48 , and $72 \mathrm{~h}$ in an identical medium containing $0.35 \mathrm{mM}\left[{ }^{14} \mathrm{C}\right]$ proline $(94 \mathrm{mCi} / \mathrm{mmol}$ ). All tissue culture wells were supplemented every $24 \mathrm{~h}$ to provide 0.1 $\mathrm{mM}$ fresh ascorbic acid. Preliminary experiments demonstrated no difference in growth rates between cells cultured in $40 \mu \mathrm{M}$ or $0.174 \mathrm{mM}$ proline over a 14-day period. $15 \mathrm{~min}$ before the end of the radiolabeling period, $2.5 \mu \mathrm{Ci}$ of $\left[{ }^{3} \mathrm{H}\right]$ inulin was added as an extracellular fluid marker, and the contents of each well thoroughly mixed. At the termination of the radiolabeling period, medium was rapidly aspirated, the plate placed on ice, and $2 \mathrm{ml}$ of cold $0.2 \mathrm{~N}$ perchloric acid poured onto the cell layer. No attempt was made to rinse the cell layer to remove residual medium, to avoid loss of intracellular free proline. The media and cell layers of three wells were pooled as one sample for analysis.

Medium samples were precipitated overnight in $75 \%$ ethanol at $-5^{\circ} \mathrm{C}$, the protein precipitate separated, and the supernatant analyzed for $\left[{ }^{3} \mathrm{H}\right.$ ] inulin concentration before filtering in Centricon ${ }^{\mathrm{TM}}-3$ (Amicon Corp., Danvers, MA). After the addition of $89 \mu \mathrm{Ci}\left[{ }^{3} \mathrm{H}\right]$ proline as internal standard, amino acids were separated by solid phase extraction using AG50W-X8 $\left(\mathrm{H}^{+}\right)$columns (Poly-Prep ${ }^{\oplus}$; Bio-Rad Laboratories, Richmond, $\mathrm{CA}$ ) and $6 \mathrm{~N} \mathrm{NH}_{4} \mathrm{OH}$ as eluant. After $\mathrm{NH}_{4} \mathrm{OH}$ removal under vacuum (Speed-Vac concentrator; Savant Instruments Inc., Farmingdale, NY), purified amino acids were resuspended in $0.1 \mathrm{~N}$ $\mathrm{HCl}$ for the subsequent determination of total proline, proline specific radioactivity, and calculation of the proline and $\left[{ }^{14} \mathrm{C}\right]$ proline $/\left[{ }^{3} \mathrm{H}\right]-$ inulin ratios. Medium protein precipitate was hydrolyzed under vacuum with $6 \mathrm{~N} \mathrm{HCl}$ at $110^{\circ} \mathrm{C}$ for $18 \mathrm{~h}$ and amino acids separated as above by solid phase extraction after the addition of $3.32 \mu \mathrm{Ci}\left[{ }^{3} \mathrm{H}\right]-$ hydroxyproline as internal standard. These purified amino acids were subsequently analyzed for measurement of ${ }^{14} \mathrm{C}$ incorporation into proline and hydroxyproline.

Cell layers were scraped, briefly homogenized in cold $0.2 \mathrm{~N}$ perchloric acid, and the precipitates and acid-soluble supernatants separated. The latter were neutralized at $4^{\circ} \mathrm{C}$ with $1 \mathrm{~N} \mathrm{KOH}$ to $\mathrm{pH} 7.0$ in an automatic titrator ( $\mathrm{pH}$ meter-26/titrator 11; Radiometer, Copenhagen, Denmark) and the concentration of $\left[{ }^{3} \mathrm{H}\right]$ inulin determined before addition of $45 \mu \mathrm{Ci}$ of $\left[{ }^{3} \mathrm{H}\right]$ proline as an internal standard. The amino acids contained in this acid-soluble cell extract were separated by solid phase extraction as above, and lyophilized before measurement of cell layer-associated total free proline and proline specific radioactivity. Since values for proline $/\left[{ }^{3} \mathrm{H}\right]$ inulin and $\left[{ }^{14} \mathrm{C}\right]$ proline $/\left[{ }^{3} \mathrm{H}\right]$ inulin in medium from the same sample were known, calculation of the amount of proline and $\left[{ }^{14} \mathrm{C}\right]$ proline contributed by residual medium in the cell layer was possible in individual samples according to the extracellular marker $\left[{ }^{3} \mathrm{H}\right]$ inulin measured in the acid-soluble cell extract. The cellular free amino acid pool of proline and the ${ }^{14} \mathrm{C}$ contained in it was estimated then as the difference between this amount and the total in the acid-soluble cell extract. The contribution of medium proline was $4.27 \pm 2.21 \%$ (mean $\pm \mathrm{SD}$ ) of the total cell-associated free proline. The cell layer's perchloric acid precipitate was lipid extracted and consecutively subjected to alkaline and acid hydrolysis for the measurement of total RNA, DNA, and separation of protein (22). The final protein precipitate was hydrolyzed overnight in $6 \mathrm{~N} \mathrm{HCl}$ as described above, $\left[{ }^{3} \mathrm{H}\right]$ hydroxyproline internal standard added, and amino acids purified and separated for the quantitation of ${ }^{14} \mathrm{C}$ incorporation into proline and hydroxyproline.

Measurement of production of ECM components. In experiments in which specific ECM components were studied, their production was quantified as the total amount accumulated in the tissue culture medium during $24 \mathrm{~h}$. At the start of this period, growth medium was changed to one with a composition similar to that for radiolabeling experiments, except for the absence of $\left[{ }^{14} \mathrm{C}\right]$ proline and the replacement of Nu-Serum by $1 \%$ FCS. Medium containing only $1 \%$ FCS was used because the presence of $\mathrm{Nu}$-Serum or greater concentrations of FCS resulted in increased backgrounds and reduced sensitivity of the ELISA used in the measurement of ECM components. Removal of all 
serum during the collection period caused both rounding and detachment of some cells and low recovery rates (3\% or less) of added purified ECM components by ELISA. The incubation conditions selected for the collection period resulted in recoveries of 96,62 , and $89 \%$ of added purified collagen I, collagen IV, and fibronectin standards, respectively. The cells from which the culture medium was obtained were harvested by treatment with trypsin and counted, or homogenized in cold perchloric acid for the extraction of RNA and DNA as noted above.

ELISA. The amount of specific ECM components secreted into the culture medium was quantified by ELISA, using a modification of a procedure previously described (23). Harvested culture medium was clarified by low speed centrifugation and, except for measurement of laminin, diluted $1 / 2$ in $1 \%$ FCS-containing fresh medium and $100 \mu \mathrm{l}$ added in quadruplicate to wells of a 96-well ELISA plate (Falcon Labware, Becton, Dickinson, \& Co., Lincoln Park, NJ). All incubations were carried out for $18 \mathrm{~h}$ at $4^{\circ} \mathrm{C}$. Purified matrix components, diluted in the same medium, were added $(0.5 \mathrm{ng}-1 \mu \mathrm{g} /$ well $)$ to each assay plate as standards. At the end of the incubation period, the medium sample was removed, and the unoccupied sites blocked by 2-h treatment with $200 \mu \mathrm{l}$ of $5 \%$ nonfat dry milk (Carnation Co., Los Angeles, CA) in PBS containing $0.05 \%$ Tween. Wells were then washed four times with PBS/Tween and incubated for $3 \mathrm{~h}$ with $100 \mu \mathrm{l}$ of rabbit antisera for specific ECM components. After extensive washing of the wells, an enzyme-linked alkaline phosphatase-labeled goat anti-rabbit IgG (Organon Teknika, Durham, NC) was added and the plates were incubated for an additional 3-h period. This was followed by extensive washing and the addition of $100 \mu \mathrm{l}$ of a phosphatase substrate solution (Sigma Chemical Co.). Color intensity was measured with a Titertek Multiscan MCC/340 (Flow Laboratories, McLean, VA), and results analyzed in a Curve-fitter computer program (Interactive Microware Inc., State College, PA).

Immunostaining. An alkaline phosphatase avidin-biotin assay was used to visually assess the production of cell-associated ECM components. Mesangial cells, cultured as described above on flexible membranes, were subjected to a 24-h stretch period or maintained in static conditions. While attached to the supporting circular membrane, cells were fixed in acetone for $10 \mathrm{~min}$ at $4^{\circ} \mathrm{C}$ and pie-shaped wedges of membrane were cut. These sections were incubated $30 \mathrm{~min}$ at room temperature with an antibody directed against specific ECM components, then washed extensively with PBS. After an additional 20-min incubation with a biotinylated anti-rabbit immunoglobulin (StrAviGen ${ }^{\text {TM }}$ Supersensitive kit AA005R; BioGenex Laboratories, San Ramon, CA), an alkaline phosphatase-conjugated strepavidin was added. Finally, a substrate (fast red in naphthol phosphate) was applied and sections incubated for $20-40 \mathrm{~min}$ to allow for color development. The slides were counterstained in Mayer's hematoxylin for $5 \mathrm{~min}$, rinsed in water, immersed in $0.1 \%$ ammonia water, and mounted in Crystal Mount (Biomedia Corp., Foster City, CA).

Chromatography. Amino acids were analyzed as their precolumndansylated derivatives by reverse phase HPLC using a modification of a previously described method (24). Derivatization of purified amino acids was carried out at room temperature at pH 9.0 in a $3.5: 1$ molar ratio of 5-dimethylaminonaphthalene-1-sulfonyl (dansyl) chloride/ amino acids for $20 \mathrm{~h}$. Preliminary work on reaction rates of individual amino acids with dansyl chloride demonstrated that this low ratio (25) maintains quantitative maximal yields of proline and hydroxyproline, while limiting the derivatization of most other amino acids and decreasing the formation of fluorescent by-products. Analyses were performed using a 344 HPLC (Beckman Instruments, San Ramon, CA) and $0.05 \mathrm{M}$ monosodium phosphate/acetic acid buffer, $\mathrm{pH} 7.0$, as the initial eluant and acetonitrile as the final eluant. Lyophilized derivatives were resuspended in the initial buffer eluant, filtered through $0.45-\mu \mathrm{m}$ filters (Acrodisc; Gelman Sciences Inc., Ann Arbor, MI) and 46- or 355-nmol amino acid residues used for analysis of samples from supernatants and protein precipitates, respectively. A linear gradient between 10 and $25 \%$ acetonitrile at $1.5 \mathrm{ml} / \mathrm{min}$ flow rate resulted in optimal separation of hydroxyproline and proline in $46 \mathrm{~min}$. The column effluent was monitored for fluorescence (Spectroflow 980 fluores- cence detector; Applied Biosystems, Ramsey, NJ) at 350-nm excitation and 470-nm emission wavelengths, and $0.3-\mathrm{ml}$ fractions collected for measurement of ${ }^{3} \mathrm{H}$ and ${ }^{14} \mathrm{C}$ content. The recovery of the ${ }^{3} \mathrm{H}$-labeled proline and hydroxyproline was $73.5 \pm 15.5 \%$ and $77.5 \pm 15.0 \%$, respectively.

All radioactivity measurements were carried out using Optiphase Hisave II (LKB Scintillation Products, Loughborough, UK) as scintillator in a three-channel liquid scintillation counter providing accurate compensation for the effect of quench (LS-3801; Beckman Instruments, Irvine, CA).

Chemical measurements. RNA was measured by the orcinol reaction for quantitation of its ribose content. With this method $1 \mu \mathrm{g}$ of yeast RNA (type I; Sigma Chemical Co.) is equivalent to $0.6 \mu \mathrm{g}$ of ribose (26). DNA was measured by its ultraviolet absorption by a two wavelength ratio method (27) using calf-thymus DNA (type I; Sigma Chemical Co.) as reference standard. Total amino acids were quantified by a modified ninhydrin method (28) using 1-leucine as standard.

Expression of results and statistical analyses. Results were expressed as per milligram DNA or per number of cells and presented as means \pm SD with the number of observations in parenthesis. With the methods used, the cellular content of DNA was $27.4 \pm 1.74 \mathrm{pg}$. The total collagen synthesis rate was expressed according to the amount of $\left[{ }^{14} \mathrm{C}\right]-$ proline incorporated into protein-associated $\left[{ }^{14} \mathrm{C}\right]$ hydroxyproline, while the incorporation into protein-associated $\left[{ }^{14} \mathrm{C}\right]$ proline was considered as index of total protein synthesis. All results were adjusted for recovery rates of pure radiolabeled internal standards. Incorporation values were corrected for the mean specific radioactivity of the endogenous pool of free proline during the labeling period, and presented as nanomoles of free intracellular proline incorporated into medium or cell layer protein. Time-dependent variables were assessed by regression analysis. Differences between groups were evaluated using Student's $t$ test for nonpaired or paired samples, where appropriate, and the distribution of $t$ in a two-tailed test. Comparisons between tissue culture groups of different cell density and those variably subjected to mechanical strain were carried out by two-way analysis of variance. Significance was set at the $5 \%$ level.

\section{Results}

Ex vivo glomerular compliance. The mean volume of dissected, nonperfused glomeruli in suspension $\left(V_{0}\right)$ was $1.907 \pm 0.601 \times 10^{6} \mu \mathrm{m}^{3}(n=5$ rats, 160 glomeruli $/$ rat $)$. Perfusion at increasing flow rates resulted in progressive glomerular expansion which correlated significantly with the associated increment in PIP. This pressure/volume relationship was linear $\left(R^{2}=0.824 \pm 0.122, n=13\right)$ over the range of pressures examined (Fig. 2). Glomerular compliance, expressed as the mean slope of this positive linear relationship, was $7.68 \times 10^{3}$ $\mu \mathrm{m}^{3} / \mathrm{mmHg}$. The presence of Bowman's capsule did not appreciably influence compliance (with capsule, 8.61 $\pm 0.82[n=8]$; without capsule, $6.89 \pm 2.78 \times 10^{3} \mu \mathrm{m}^{3} / \mathrm{mmHg}[n=5], P$ $=0.12$ ). Total mean volume increased by $1.162 \times 10^{6} \mu \mathrm{m}^{3}$ $\left(61 \%\right.$ over mean $V_{0}$ ) when the PIP was progressively increased from 0 to $150 \mathrm{mmHg}$. Since the efferent arteriole remained open, distal intraglomerular pressure was 0 , while mean intracapillary pressure may have approximated a value of one-half the PIP value, assuming a linear decrease in pressure along the capillary bed. In addition, pressure outside the capillary within Bowman's space was obviously absent. Therefore, mean intracapillary pressure in ex vivo perfused glomeruli is equivalent to the transcapillary pressure difference in vivo. Reported values for mean transcapillary pressure difference in physiological and various pathological conditions have varied between 32 and $52 \mathrm{mmHg}(1,29)$. These transcapillary pressures would correspond to our PIPs of 62 and $104 \mathrm{mmHg}$. Our measured increment in glomerular volume over this range of pressures 


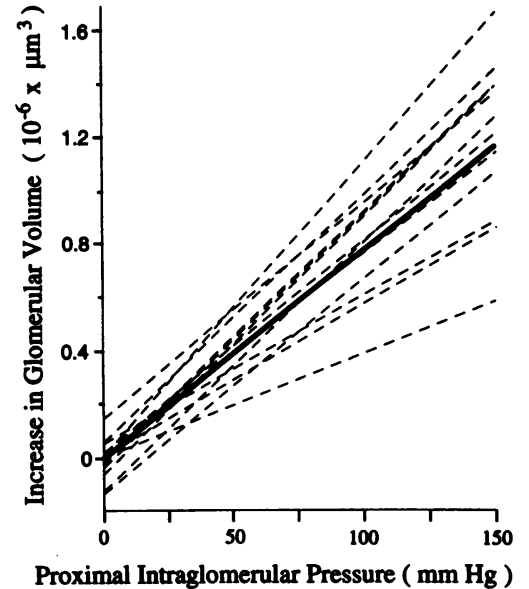

Proximal Intraglomerular Pressure ( $\mathrm{mm} \mathrm{Hg}$ )
Figure 2. Linear regressions $(P<0.004)$ defining the relationship between proximal intraglomerular pressure and the increment in intraglomerular volume in 13 perfused glomeruli. The volume increment is that value above the initial, nonperfused glomerular volume.

Dashed lines represent results in separate glomeruli; the continuous line is the mean regression for all values.

$\left[\left(V_{104}-V_{62}\right) \times 100 / V_{62}\right]$ indicates that the increased pressure expanded the glomerulus by $16 \%$, considering a $V_{0}$ equal to the mean value of suspended glomeruli independently obtained in similar rats.

Dissected glomeruli varied considerably in their overall size. To determine whether these differences influenced compliance, the PIP/volume regression slopes were separately analyzed for large and small glomeruli. $A V_{0}$ of $2 \times 10^{6} \mu \mathrm{m}^{3}$ was arbitrarily chosen as the dividing criterion. The difference in the pressure/volume slopes between both groups of glomeruli did not reach significance $(8.73 \pm 1.57[n=8]$ and $6.69 \pm 1.9$ $\times 10^{3}[n=5] \mu \mathrm{m}^{3} / \mathrm{mmHg}$ for $\mathrm{V}_{0}>2$ and $\leq 2 \times 10^{6} \mu \mathrm{m}^{3}$, respectively, $P=0.059$ ). However, a closer examination of results from glomeruli of markedly different $V_{0}$ demonstrated that in small glomeruli the pressure/volume relationship at PIP above $100 \mathrm{mmHg}$ was best expressed as a curvilinear plot (Fig. 3). These data suggest that the smaller glomeruli are less compliant (greater rigidity) and demonstrate lesser degrees of expansion than larger glomeruli at PIPs greater than 80-100 $\mathrm{mmHg}$, i.e., at about the upper limits of the corresponding pathophysiological range of mean transcapillary pressure.

Glomerular volume change in vivo. Encumbered by the resilience of surrounding structures, glomeruli in vivo may not expand as intraglomerular pressure increases. To determine whether glomerular compliance also permits volume changes to occur in situ as they do ex vivo, kidneys were fixed in vivo while subjected to different perfusion pressures. As compared to values obtained in nonperfused, immersion-fixed tissue, volume was consistently greater in both the outer and inner cortical glomeruli of perfused kidneys (Table I). This increase in volume, compared to nonperfused contralateral kidneys, achieved statistical significance at perfusion pressures of 130 and $150 \mathrm{mmHg}$ ( 27 and $38 \%$ increase, respectively) (Table I). Although glomerular volume in the nonperfused kidneys is analogous to the $V_{0}$ of dissected glomeruli in suspension, glomerular volume in kidneys perfused at specific pressures may not be precisely related to results ex vivo because increased pressure during perfusion via the abdominal aorta does not strictly correlate with PIP changes.

The width of the peripheral glomerular basement membrane tended to thin as the glomerular volume increased (Table I). This thinning was most evident in the outer cortex, but only achieved statistical significance at perfusion pressures of $150 \mathrm{mmHg}$ ( $7 \%$ decrease).

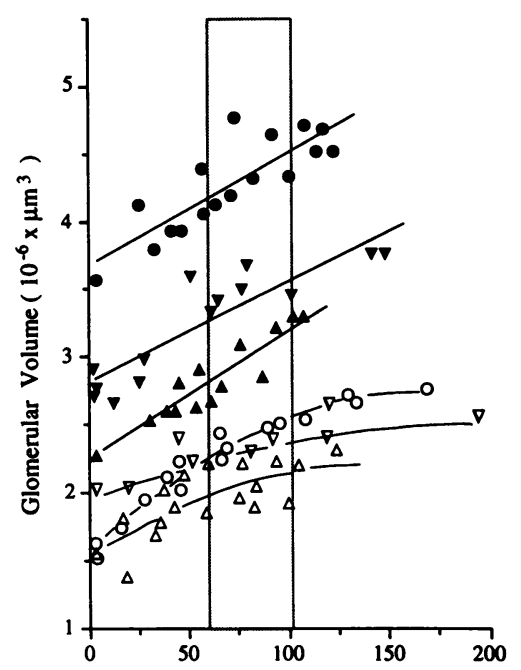

Proximal Intraglomerular Pressure $(\mathrm{mm} \mathrm{Hg})$
Figure 3. Relationship between glomerular volume and proximal intraglomerular pressure in six perfused glomeruli selected by their distinctively different initial volumes at 0 perfusion pressure. For comparison purposes, results were arbitrarily divided into those in large (closed symbols) and those in small (open symbols) glomeruli according to an initial volume greater or less than $2 \times 10^{6} \mu \mathrm{m}^{3}$, and linear or first-degree polynomial regressions fitted, respectively. Values within the dashed area represent proximal intraglomerular pressures that may approximate mean glomerular transcapillary pressure differences of 32-52 $\mathrm{mmHg}$.

Total collagen synthesis by mesangial cells during mechanical strain. Confluent cultures of mesangial cells ( $5 \mathrm{~d}$ after seeding, containing $\sim 2.74 \pm 0.55 \times 10^{6}$ cells $/$ sample of three wells at the start of the experiments) did not change their cell size (similar mean RNA/DNA values in all groups of $337 \pm 140$ $\mu \mathrm{g} / \mathrm{mg}$ ) or cell number (sample's DNA) (Fig. 4) during 24$120 \mathrm{~h}$ of mechanical stretching. In addition, the disappearance rate of exogenous proline from culture media during incubation was also unaffected, declining linearly $\left(R^{2}=0.91\right)$ with time at a rate of $4.15 \pm 0.26(n=55) \mathrm{nmol} / \mathrm{h}$ per $\mathrm{mg}$ DNA in control and experimental groups. After the addition of exogenous proline at the start of radiolabeling, the endogenous pool size of the amino acid increased markedly during the first $48 \mathrm{~h}$ and subsequently manifested a small decline. The specific ra-

Table I. Effects of Renal Perfusion Pressure on Glomerular Volume and Peripheral Basement Membrane Thickness

\begin{tabular}{|c|c|c|c|c|}
\hline \multirow[b]{2}{*}{$\begin{array}{c}\text { Perfusion } \\
\text { pressure }\end{array}$} & \multicolumn{2}{|c|}{ Glomerular volume } & \multicolumn{2}{|c|}{$\begin{array}{l}\text { Basement membrane } \\
\text { thickness }\end{array}$} \\
\hline & $\begin{array}{l}\text { Inner } \\
\text { cortex }\end{array}$ & $\begin{array}{l}\text { Outer } \\
\text { cortex }\end{array}$ & $\begin{array}{l}\text { Inner } \\
\text { cortex }\end{array}$ & $\begin{array}{l}\text { Outer } \\
\text { cortex }\end{array}$ \\
\hline $\mathrm{mmHg}$ & \multicolumn{2}{|c|}{$10^{-3} \times \mu m^{3}$} & \multicolumn{2}{|c|}{$n m$} \\
\hline 0 (right) & $273 \pm 92$ & $221 \pm 59$ & ND & $168 \pm 11$ \\
\hline 110 (left) & $353 \pm 45$ & $275 \pm 68$ & $168 \pm 7$ & $166 \pm 5$ \\
\hline 0 (right) & $270 \pm 86$ & $223 \pm 46$ & $176 \pm 7$ & $173 \pm 10$ \\
\hline 130 (left) & $340 \pm 60$ & $283 \pm 41^{*}$ & $176 \pm 7$ & $170 \pm 8$ \\
\hline 0 (right) & $345 \pm 53$ & $250 \pm 34$ & ND & $176 \pm 5$ \\
\hline 150 (left) & $434 \pm 96$ & $345 \pm 60^{*}$ & $162 \pm 12$ & $164 \pm 12^{\ddagger}$ \\
\hline
\end{tabular}

Results obtained in the perfused left kidney were compared to those in the nonperfused right kidney from the same animal. Values are reported as mean \pm SD. Volume and thickness data were obtained in $21 \pm 7$ glomeruli and $146 \pm 35$ measurements, respectively. Each group contained eight rats.

$* P<0.02$.

${ }^{\ddagger} P<0.05$. 


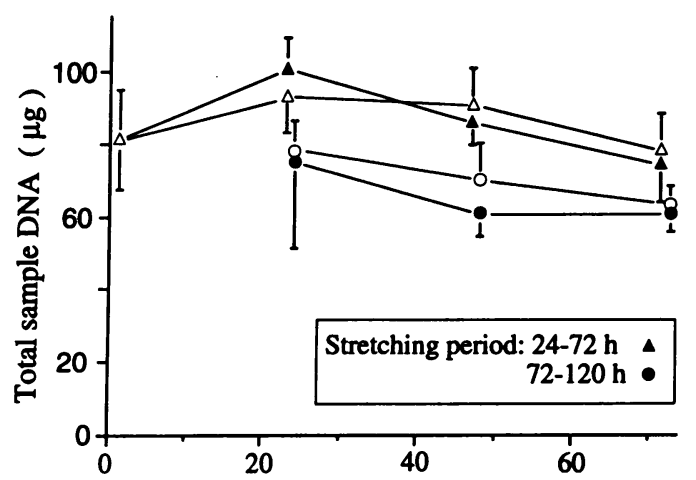

Period of radiolabeling for synthesis measurement (h)

Figure 4. DNA quantity in specimens of confluent cultures of mesangial cells during mechanical strain (closed symbols) or static (open symbols) incubation conditions. Radiolabeling was carried out during the last 24-72 $\mathrm{h}$ of the experimental period in all groups. Data points are reported as the mean \pm SD of four to eight samples, each originated by combining cells from three culture wells.

dioactivity of the proline endogenous pool was maximal, approaching that of proline in the medium, at $24 \mathrm{~h}$. This was followed by a steady decline due to the cellular generation of new proline. These changes, however, were similar in static and stretched cultures (Fig. 5). The secretion of collagen into the medium, i.e., the amount of intracellular free proline incorporated into protein-associated hydroxyproline, increased linearly with the duration of labeling (Fig. 6) denoting a constant rate of secretion. In these confluent cultures, the quantity of

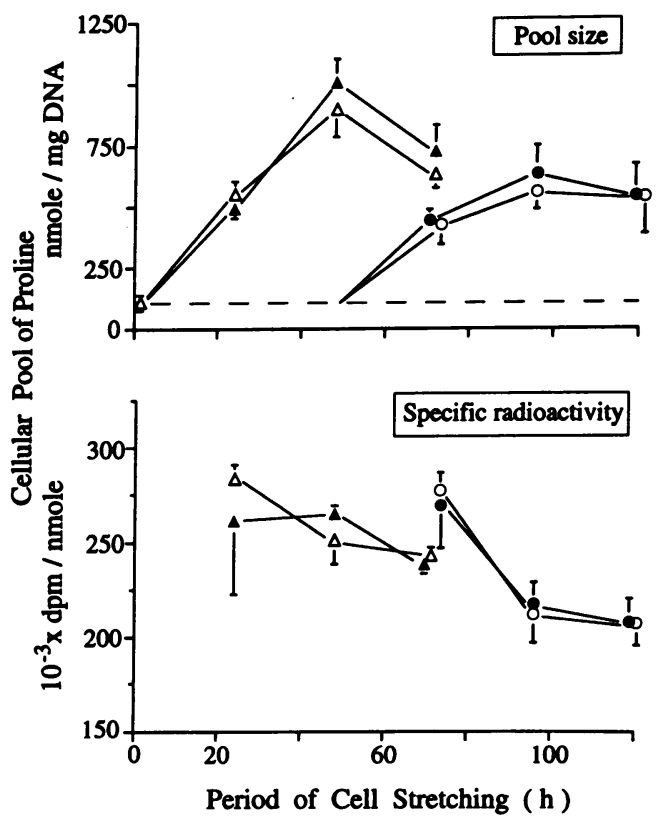

Figure 5. Changes in the cellular pool of free proline and its specific radioactivity during $3 \mathrm{~d}$ after the addition of radiolabeled proline to the incubation medium. Results were obtained in the same confluent cultures of mesangial cells as in Fig. 4. Cultures were maintained in static conditions $(\Delta, 0)$ or under mechanical strain for up to $72(\Delta)$ or $120 \mathrm{~h}(\bullet)$. Data points are reported as the mean \pm SD of four to eight samples, each originated by combining cell layers from three culture wells.

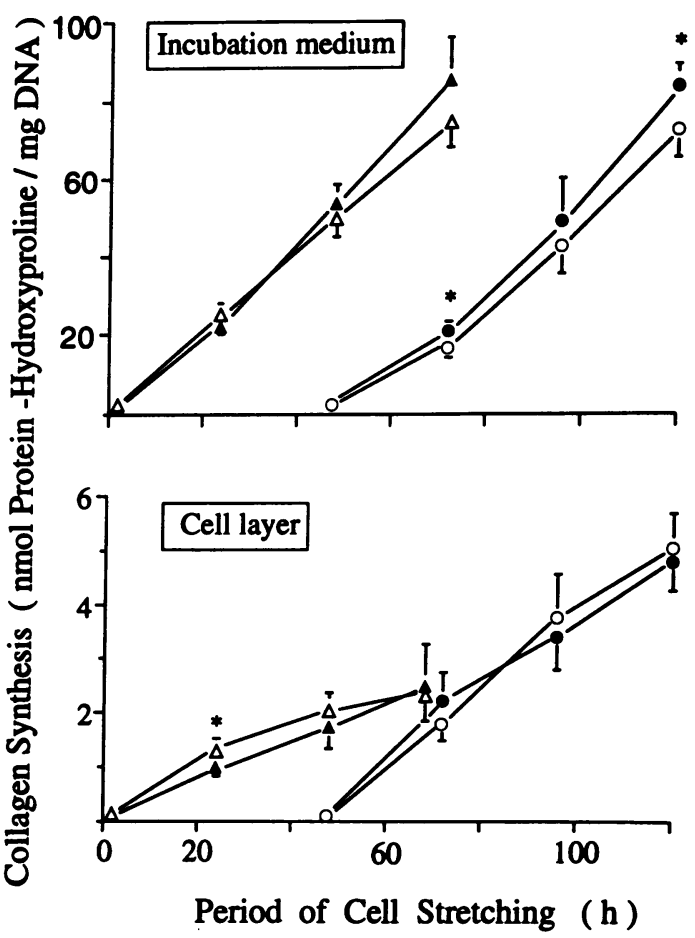

Figure 6. Total collagen synthesis in confluent cultures of mesangial cells maintained in static conditions $(\Delta, 0)$ or under mechanical strain for up to $72(\Delta)$ or $120 \mathrm{~h}(\bullet)$. Results were obtained in the same confluent cultures of mesangial cells as in Figs. 4 and 5. Data points are reported as the mean \pm SD of four to eight samples, each originated by combining the contents from three culture wells. *Statistically significant differences between groups $(P<0.05)$.

collagen secreted was significantly greater when maintained under cyclic stretching for $72 \mathrm{~h}$ or more as compared to static controls (Fig. 6). The increased synthesis was probably not limited to collagenous proteins, since the incorporation of intracellular proline into protein-associated proline in the medium was also significantly increased $(645 \pm 60[n=8]$ vs $538 \pm 47[n=8] \mathrm{nmol} / \mathrm{mg}$ DNA, $P=0.016$, at $120 \mathrm{~h}$ stretching and $72 \mathrm{~h}$ radiolabeling) while maintaining similar $\left[{ }^{14} \mathrm{C}\right]-$ proline $/\left[{ }^{14} \mathrm{C}\right]$ hydroxyproline ratio at all periods studied (stretched: $6.37 \pm 1.25[n=28$ ], static: $6.40 \pm 1.08[n=27]$ ). Although there were no significant differences in DNA content between groups, analysis of the amount of collagen produced in individual samples of cultures stretched for 72-120 h and their corresponding static controls, demonstrated a negative linear relationship between the rate of collagen synthesized into the medium and DNA $\left(\mathrm{R}^{2}=0.604\right.$ and $0.948, P<0.001$ for stretched and static cultures, respectively) (Fig. 7).

As compared to results in the medium, synthesis of cell layer-associated collagen was only a small fraction the total newly deposited protein $\left(\left[{ }^{14} \mathrm{C}\right]\right.$ proline $/\left[{ }^{14} \mathrm{C}\right]$ hydroxyproline, stretched: $363 \pm 90[n=28]$, static: $328 \pm 53[n=27])$ and markedly less than the amount secreted (Fig. 6). Mechanical strain induced only an early small decrease in the rate of collagen deposited in the cell layer without apparent effect at periods beyond $24 \mathrm{~h}$.

Synthesis of specific ECM components by mesangial cells during mechanical strain. Since the total quantity of collagen synthesized by mesangial cells appeared to be enhanced in cultures with lower number of cells, ECM production was further 


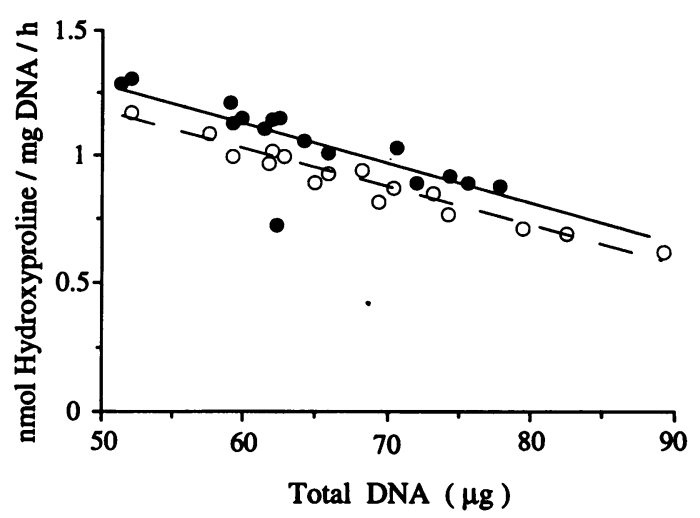

Figure 7. Relationship between cell density and the rate of secretion of total collagen into the medium. Results were obtained in the same confluent cultures of mesangial cells during 72-120 h of mechanical strain (closed symbols) or static control (open symbols) incubation conditions as in Figs. 4-6.

studied at different degrees of cell density $\left(0.13\right.$ to $0.51 \times 10^{6}$ cells/sample of three wells at the start of the experiments) grown in static conditions or during mechanical strain beginning 18-24 $\mathrm{h}$ after seeding and for periods of 72,120 , and 168 h. A significant negative relationship between the sample's total DNA and RNA/DNA was demonstrated in plates grown under mechanical strain $\left(\mathrm{R}^{2}=0.454, P<0.001\right)$ or static conditions $\left(\mathrm{R}^{2}=0.551, P<0.001\right)$; i.e., cell size diminished as cell density in the plate increased. Measurement of ECM secretion into the medium during the last $24 \mathrm{~h}$ of each experimental period demonstrated marked differences in the accumulation of individual components as cell number increased (Fig. 8). In both experimental and control groups, collagen I, collagen IV, and laminin production was highest initially and then it declined rapidly, while fibronectin, undetectable in early cultures, demonstrated maximal accumulation after 4-5 d. Collagen IV production was characteristically three- to fourfold greater than collagen I in all groups and at all time periods ( Fig. 8). At periods of maximal ECM formation, mechanical strain significantly increased the production of collagen IV, collagen I, fibronectin, and laminin (Fig. 8). This effect was less apparent as the cell number increased and ECM production diminished, even though this coincided with longer periods of cell stretching. Cultures subjected to mechanical strain for periods longer than $72 \mathrm{~h}$ also demonstrated lower cell number than controls (Fig. 8). Therefore, results in all experimental and control groups available in three separate experiments, which included a wide range of cell densities, were further analyzed to determine the effect of cell number on collagen IV production. An inverse relationship between cell density and collagen IV production was evident in both control and stretched cultures (Fig. 9). In addition, examination of the results by analysis of variance demonstrated that both cell density and mechanical strain significantly and independently $(P<0.001$ and $P$ $=0.006$, respectively) influenced collagen IV production with no interaction. Separation of samples in groups of high and low cell number according to the mean cell content for all samples $\left(1.5 \times 10^{6}\right.$ cells $)$ evidenced the combined effect of mechanical stress and low cell density in enhancing collagen IV synthesis (Fig. 9).

Since the force applied to the bottom of the culture wells does not produce a uniform mechanical strain throughout the
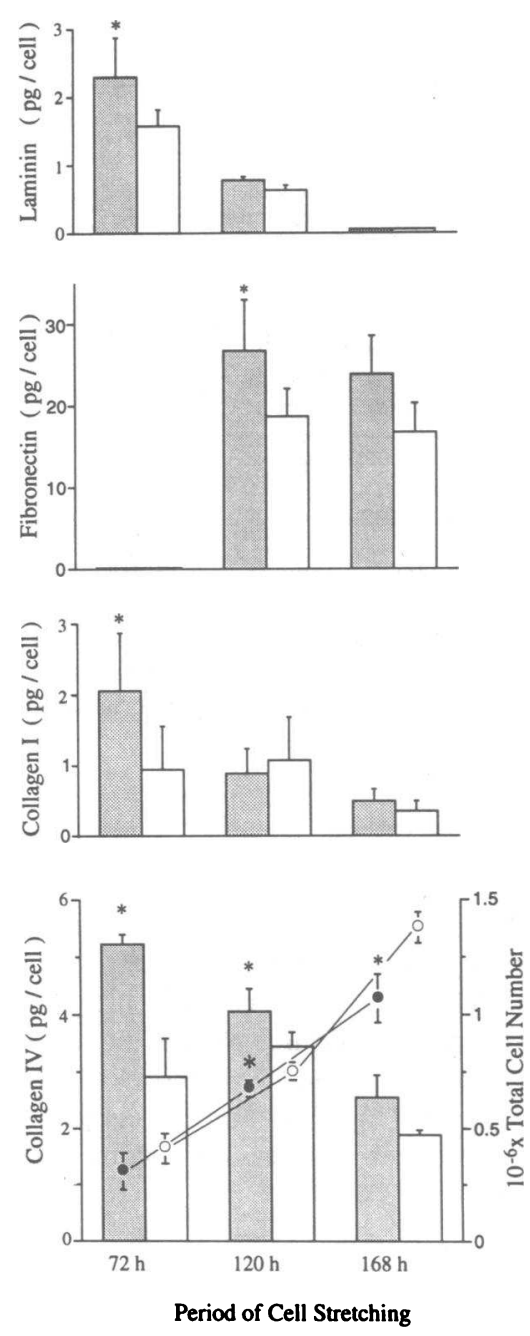

Figure 8. Production of extracellular matrix components in subconfluent mesangial cell cultures grown in static (open bars) or under mechanical strain conditions (shaded bars). Results were obtained in medium from 24-h incubations ending at the indicated study period. The cell number in static $(0)$ and stretched cultures $(\bullet)$ during the experiments is shown. Values are reported as the mean \pm SD of four to six samples, each originated by combining media or cells from three culture wells. *Statistically significant differences between groups $(P<0.05)$.

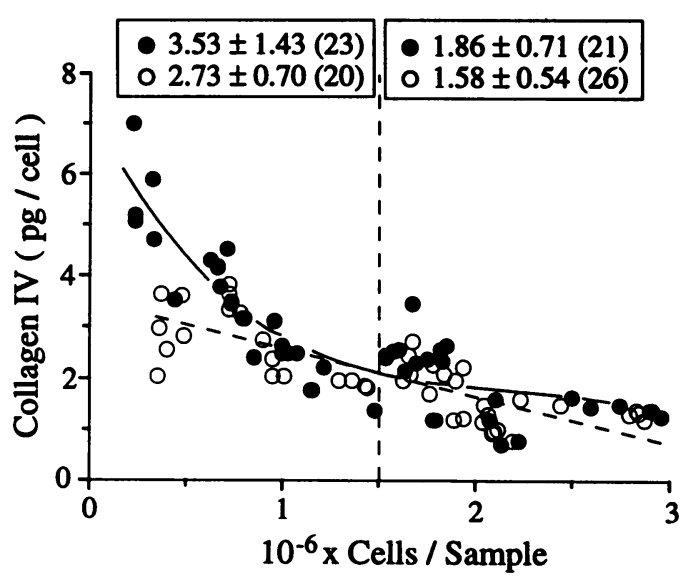

Figure 9. Relationship between collagen IV production in the medium over $24 \mathrm{~h}$ and cell density in cultures of mesangial cells grown under mechanical strain $(\bullet)$ and in their paired (for initial cell density and period of observation) controls grown in static conditions (o). Mechanical strain was applied for periods between 72 and 168 h. Data points are results in separate samples originated by combining media or cells from three culture wells. Mean \pm SD collagen production/cell in stretched and control cultures containing cell numbers above and below the average value for all groups $\left(1.5 \times 10^{6}\right)$ is presented (number of samples in parentheses). Linear (dashed line) and third degree polynomial (continuous line) regressions for stretched and control cultures, respectively, are shown. 
cell layer, additional studies were aimed at identifying whether the intensity of stretching influenced ECM production. Immunohistochemical evaluation of collagen IV production in different zones of the same culture well demonstrated dense granular cytoplasmic staining in cells located within the area of maximal mechanical strain (Fig. 10). This staining decreased markedly in zones subjected to lesser degrees of strain, being similar to that in all zones of control static cultures in the most inner zone of the culture well, where strain intensity approached zero. Immunohistochemical evaluation of laminin and fibronectin production demonstrated patterns of enhanced synthesis similar to those for collagen type IV, indicating that only a discrete population of cells, under significant mechanical strain, were responsible for the overall enhancement of ECM formation.

\section{Discussion}

Like its human counterparts, many experimental renal diseases relentlessly advance to end stage (30). Progressive glomerular deposition of ECM is typically found in most of these disorders. This scarring progresses without obvious dependence on the activity of the initiating cause of the renal damage $(30,31)$. While many factors complicating the course of renal disease have been identified capable of modulating the rate at which glomerular filtration fails (30), it is the increased intraglomerular pressure which has received the most attention (1-4, 32). This condition is characteristically associated with mesangial accumulation of ECM. Why increases in glomerular pres- sure should initiate progressive scarring is not apparent. Are the increase in intraglomerular pressure and the accumulation of ECM causally related? Return of glomerular pressure to normal by dietary protein restriction or the administration of converting enzyme inhibitors has predictably improved the severity of glomerular injury in experimental renal disease $(3,29$, $33,34)$. Because these dietary changes and pharmacologic agents may well be exerting other effects in addition to their hemodynamic actions $(35,36)$, the causal relationship between increased intraglomerular pressure and ECM formation has remained somewhat ambiguous. Our study suggests that by expanding glomerular capillaries and stretching the adjacent mesangial cells, glomerular hypertension stimulates mesangial matrix formation and deposition. This translation of increased pressure, a physical event, into enhanced synthesis of ECM, a metabolic event, could play a decisive role in the progression of renal disease.

Glomerular compliance can be conceptualized as the ease with which a capillary tuft expands as luminal hydraulic pressure increases. It can be quantified from the relationship between the increments in glomerular volume associated with graded increments in intraglomerular pressure. Fig. 2 clearly establishes the linearity of this pressure/volume relationship in the isolated perfused glomerulus. Regardless of the glomerulus' initial volume, increasing perfusion pressure rapidly caused progressive glomerular expansion. The pattern of pressure drop from the proximal intraglomerular site to the open efferent arteriole is unknown. If the active filtration which is observed in these glomeruli during perfusion contributes to the dissipation of pressure, a major decrement is likely to occur in

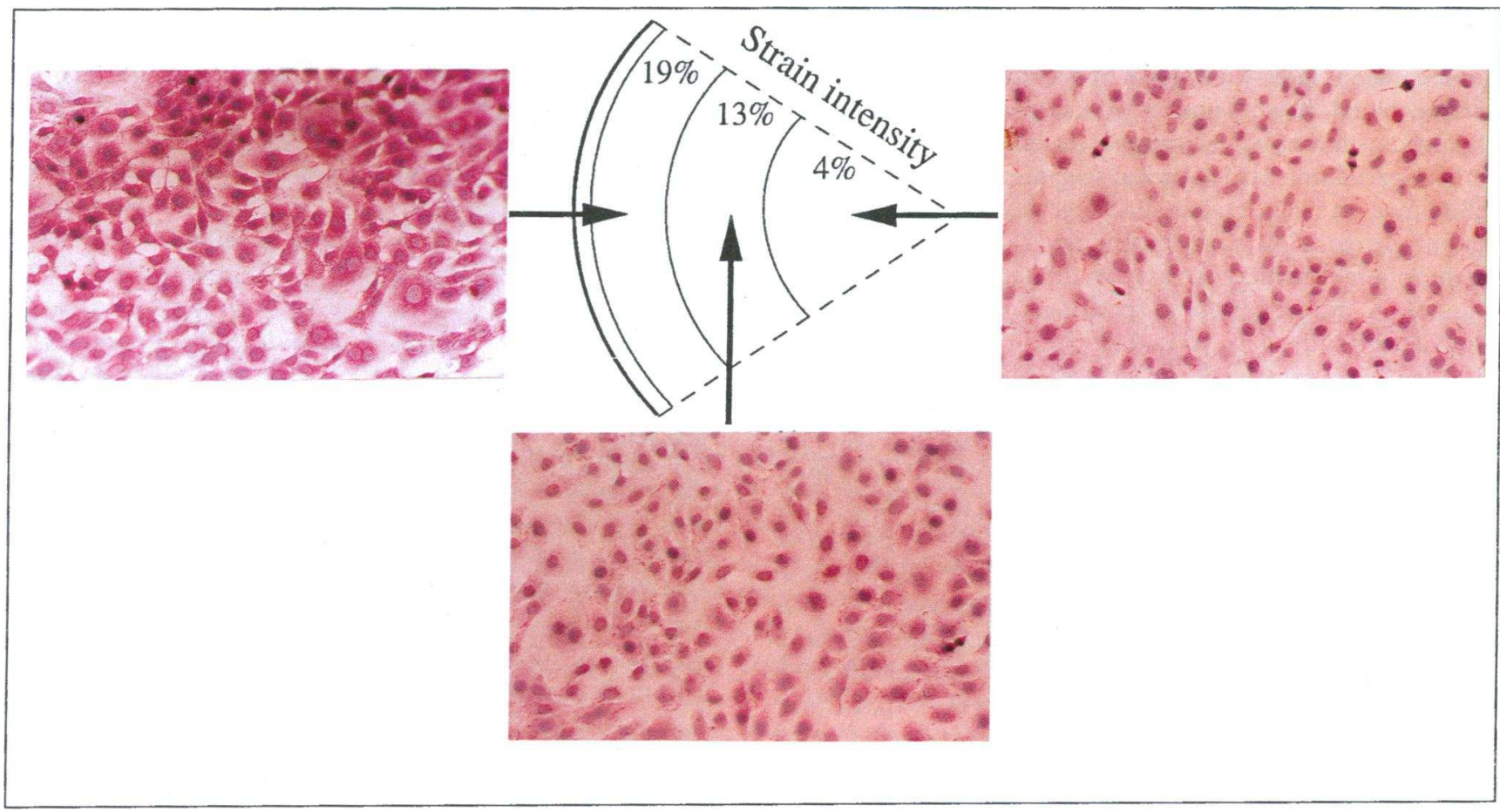

Figure 10. Collagen IV expression in mesangial cells grown under mechanical strain in cultures carried out in conditions similar to those in Fig. 8. $72 \mathrm{~h}$ after cyclic stretching, the cell layer was fixed and a pie-shaped section of a well's flexible base was cut. Immunostaining techniques were used to demonstrate the presence of collagen type IV. Collagen type IV is evidenced as a red cytoplasmic, finely granular material. The photographs were taken from the areas indicated by the arrows. The approximate mean strain intensity for regions along the radius of the specimen are shown diagrammatically. Original magnification was 50. 
the early part of the glomerular capillary where pressure is highest and filtration is brisk, resulting in overall intraglomerular pressures below one-half the value of the PIP. Albeit mean capillary pressure may be overestimated by assuming values approximating one-half of PIP, a remarkable capacity for distention was demonstrable even at very low PIP ( $<50 \mathrm{mmHg}$ ), as shown in Fig. 3. This compliance was evident over a wide range of PIPs, and thus, the volume changes observed ex vivo occurred at intraglomerular pressures well beyond the 32-52 $\mathrm{mmHg}$ limits of pathophysiologically obtainable transglomerular pressure differences. Even within this narrow range, the change in pressure allowed a $16 \%$ change in volume, presupposing a linear decline in perfusion pressure along the glomerular capillary. The thinning of the glomerular basement membrane observed histologically supports the notion that it is the individual capillary distention that accounts for the overall glomerular expansion. Previous studies have also demonstrated a similar change in basement membrane thickness in association with increased mean glomerular and capillary volume during perfusion/fixation of kidneys in situ (37).

Unlike the isolated tissue, glomerular distensibility in vivo is probably limited by the resilience of the surrounding cortical structures. In this study, however, in vivo glomerular volume changed over an ample range of renal perfusion pressures, indicating that compliance is a characteristic property of glomeruli in vivo and ex vivo. Similar results were previously obtained by others comparing glomerular volume in nonperfused, immersion-fixed specimens with that of kidneys fixed at perfusion pressures approximating the rat's mean arterial pressure (37). There are, of course, several reasons why categorical values of glomerular volume obtained in ex vivo and in vivo studies cannot be directly compared. First, although the intraglomerular pressure must be related to the corresponding renal perfusion pressure during fixation, the precise intraglomerular pressure obtained is largely unknown due to autoregulation of glomerular blood flow. Thus, a glomerular volume/pressure relationship cannot be determined. Second, measurements of glomerular volume in histological specimens are subject to the well-known artifacts of tissue shrinkage during the processes of fixation, dehydration, and embedding $(37,38)$. Indeed, with the morphometric methods used in this study, the glomerular volumes in immersion-fixed specimens were $\sim 84 \%$ lower than values obtained in isolated glomeruli in suspension.

Others have stressed the importance of glomerular size as a determinant of the wall tension created by a given level of luminal pressure (7). According to Laplace's law, the wall tension of a cylindrical membrane is a product of the transmural hydraulic pressure and the radius of the curvature of the membrane (39). Therefore, at comparable pressures, capillaries with increased cross-sectional area develop greater wall tension and they would be expected to distend more than smaller ones. The lower pressure/volume slope obtained in glomeruli smaller than $2 \times 10^{6} \mu \mathrm{m}^{3}$, although not reaching a significantly different level from the slope in larger ones $(P=0.059)$, suggests that larger capillaries are subjected to greater wall tension and distension, correlating nicely with the dictates of the Laplace's formulation. The reason for the apparent deviation from linearity of the pressure/volume relationship (i.e., increasing rigidity) in the smaller glomeruli at PIP above 100 $\mathrm{mmHg}$, remains undetermined (Fig. 3 ). If it is assumed that, even at high perfusion rates, PIP is always a reliable estimate of mean transcapillary pressure difference, then augmented mes- angial cell tone during glomerular expansion is a possible cause for this increasing rigidity.

While mesangial cell bodies are located in the axial plane of the glomerular lobule, numerous cellular projections extend between adjacent capillaries and attach to the mesangial reflections of the glomerular basement membrane (40). Because the microfilament bundles contained in these juxtacapillary processes frequently interconnect opposing parts of the basement membrane within the same glomerular lobule, marked cell stretching is likely to occur during diffuse capillary dilation (Fig. 11). From the findings obtained in the isolated perfused glomerulus it can be inferred that the intensity of this mechanical strain will depend on: $(a)$ the magnitude of the transmural pressure difference; $(b)$ the glomerular size; $(c)$ the degree of compliance of the glomerular structure. The latter, in turn, depends on the viscoelasticity of the glomerular supporting framework, mostly imparted by the isometric contraction (tone) of the mesangial cell (41) and the high flexibility of the network structure of its collagen type IV (42). Pathological increases in glomerular compliance can result from those disorders that interfere with the normal association or linkage of collagen IV molecules or with mesangial cell contractility. These disorders include human and Samoyed hereditary nephritis $(43,44)$ and diabetes mellitus in which glycosylation of collagen disrupts cross-linking $(45,46)$ and the glomerular contractile response to angiotensin II is impaired $(47,48)$.

The bulk of collagen synthesized by the mesangial cells used in this study was type IV. This component of ECM is also the most common type of collagen seen in normal glomeruli and in such pathological conditions as diabetic nephropathy (49). Other studies of collagen synthesis by mesangial cells

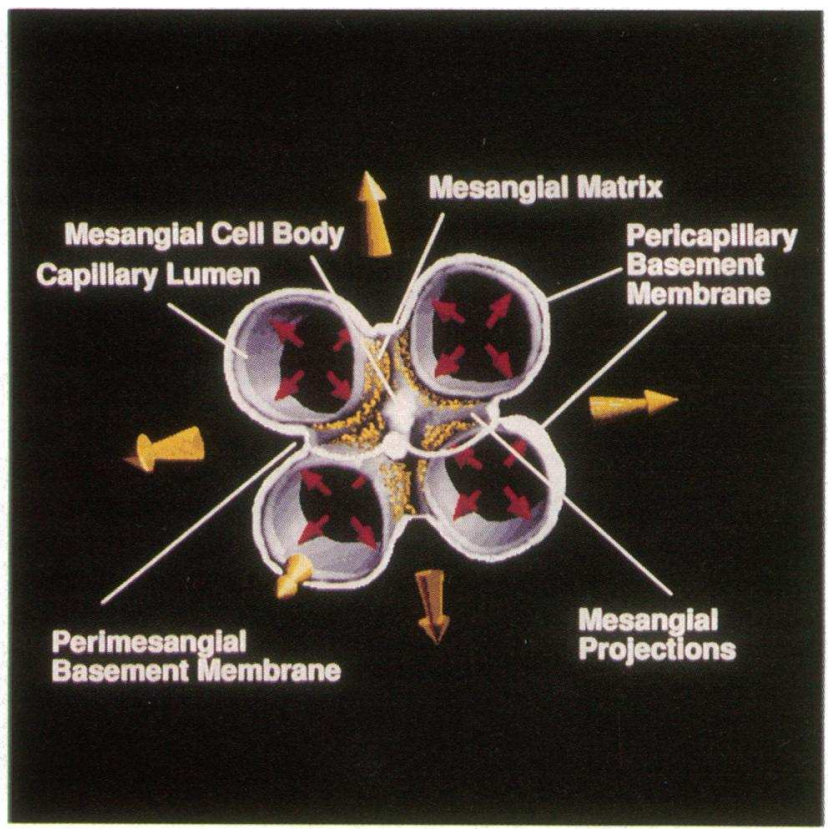

Figure 11. The central location of a mesangial cell within a glomerular lobule and its cytoplasmic intercapillary projections is depicted. Capillary expansion, a consequence of intracapillary pressure, will result in an outward pull of the perimesangial basement membrane regions and the corresponding attachment sites of the cellular projections, inducing a tridimensional cellular stretch. 
have not been able to demonstrate the appropriate dominance of type IV collagen $(50,51)$. Cyclic mechanical strain of mesangial cells not only enhanced the synthesis of proteins, including collagen type I, fibronectin, and laminin, but most significantly that of collagen type IV.

The radiolabel incorporation methods used in this study to quantitate the net rate of total collagen synthesis do not account for potential differences in intracellular precursor pool compartmentation, however, they do provide an accurate measurement of the total intracellular pool of free proline and its specific activity. Therefore, apparent alterations in the synthesis rate due to changes in the specific radioactivity of proline in the medium, proline transport rate and precursor dilution in a variable intracellular pool, are excluded. The increased synthesis of total collagen was limited to that appearing in the medium under culture conditions that inhibited cross-linking of newly formed collagen. Except for an early transient decrease, no changes were demonstrable in the measured collagen contained within the cell layer. While these studies demonstrate that enhanced net synthesis affects collagen in the culture medium during mechanical strain, the possible contribution of altered degradation cannot be ruled out.

Measurements of total collagen synthesis into the medium in confluent cultures and the identification of active secretion of ECM components by specific groups of cells suggest that the mechanically stimulated synthesis of ECM is magnified by increasing the intensity and duration of strain. In fact, the mechanical effects of stretching were highly specific, since, within the same culture well, only the fraction of cells subjected to significant strain responded with enhanced synthesis of ECM components. Normalizing the increased formation of ECM components found in the medium for all cells in the well, therefore greatly underestimated the actual production by the fraction of contributing cells.

The total $42 \%$ increase in volume of the nonperfused (undistended $)$ glomerulus during its perfusion at PIP $\left[\left(V_{104}-V_{0}\right)\right.$ $\left.\times 100 / V_{0}\right]$ resulting in transcapillary pressures approaching the upper pathophysiological limits, entails a $12 \%$ increment in the radius of the glomerular sphere. This approximates the $19 \%$ maximal degree of unidirectional stretch applied to mesangial cells in culture. However, the actual mechanical strain in situ may be considerably greater than in tissue culture, since in the former circumstance, mesangial cells are located centrally within the glomerular lobule and are subject to tridimensional stretch (Fig. 11).

In this study, repetitive stretching was arbitrarily applied at three cycles/min. It is currently unknown whether this rate approximates the oscillations in intraglomerular pressure seen under normal or pathologic conditions, nor it is yet clear whether this rate maximally stimulates metabolism of ECM. Under normal circumstances, the moment-to-moment variations in mean systemic arterial pressure of up to $32 \mathrm{mmHg}$ in the rat (52), are unlikely to induce significant changes in glomerular volume due to the precise autoregulation of intraglomerular pressure (53). However, in circumstances in which decreased preglomerular resistance and impaired or absent autoregulation of intraglomerular pressure exist, e.g., in residual glomeruli of the remnant kidney (53-55), in chronic passive Heymann glomerulonephritis (56) and in poorly controlled experimental diabetes (57), a more complete intraglomerular transmission of systemic arterial pressure and its oscillations is permitted. In these conditions, mean intraglomerular pressure variation caused by changes in systemic pressure may approach $10 \mathrm{mmHg}(52,53)$. Further, the fast and high amplitude pulses of the systemic arterial pressure are transmitted intraglomerularly, inducing intracapillary oscillations of $\sim 10$ $\mathrm{mmHg}$ under normal conditions (58). It is not known, however, if this transmission is enhanced in situations of decreased preglomerular resistance. In combination, both these sources for variation in intraglomerular pressure may cause significant glomerular distension, since normal glomerular compliance in the rat will allow an increase in volume of $\sim 0.4 \%$ per $\mathrm{mmHg}$ of pressure change, as determined in this study.

How mechanical stimuli become translated into altered metabolic activity is currently unknown. The cellular sensor mechanism may involve the cytoskeletal and ECM connections formed by integrins (59). It has been suggested that cAMP may be involved in the increased total protein and collagen synthesis that has been demonstrated in cyclically stretched smooth muscle cells $(60,61)$. Mechanical stretching of the apical membrane of renal proximal tubules activates specific calcium-permeable cation channels, suggesting that changes in cytosolic calcium may be involved in the transmission of the signal (62). It is unlikely, however, that the metabolic response induced by mechanical stimulation of mesangial cells is due to the direct effect of released growth factors. If factors released into the medium were the proximate stimulus for ECM synthesis, then obviously all cells, and not just those subjected to the greatest strain, should increase their production rates. It could be argued, however, that the release of growth factors is indeed important, but that only stretched cells are capable of responding to the stimulus due to enhanced receptor expression or to some other intrinsic change in these cells.

Although the stimulating effect of mechanical strain on ECM production was demonstrable in both confluent and subconfluent cultures, the synthesis of ECM components was closely related to the rate of mesangial cell growth; subconfluent cultures with replicating hypertrophied cells (i.e., increased RNA/DNA ratios) demonstrated greater production rates as compared to highly confluent quiescent cultures. This observation agrees with other reports that also directly linked the rate of collagen synthesis with that of mesangial and arterial smooth muscle cell growth in culture (63-65). The in vivo relevance of these findings is evidenced by the progressive glomerulosclerosis occurring in the hypertrophied glomeruli of mice transgenic for growth hormone, where excessive deposition of ECM is closely associated with increased cell turnover (66).

The close relationship between mesangial cell growth and ECM production suggests that excessive collagen formation may also be stimulated by glomerular hypertrophy and hyperplasia despite the absence of increased intracapillary pressure. Glomerular compensatory hypertrophy, in turn, is associated with increased capillary mean cross-sectional area and expanded volume of the capillary lumen (67). As discussed above, the larger radius of the hypertrophied capillaries in these residual glomeruli translates even normal intraglomerular pressure into an increased wall tension, exaggerated glomerular expansion and increased mesangial cell stretch. In this formulation, glomerular cell hypertrophy and increased mesangial cell mechanical strain should exert additive effects on the accumulation of ECM and progression of glomerular injury. Conditions spawning these combined pathophysiological forces in- 
clude subtotal nephrectomy $(6,7,14,68)$, genetically defined increased glomerular growth (8), disproportionate growth hormone action (63), streptozotocin-induced diabetes $(10,69$, 70 ), and excessive protein intake $(10,40,71)$. Superimposition of increased intraglomerular pressure should worsen these pernicious events.

In most circumstances, two or more mechanical factors coexist with enhanced cell growth causing an additive effect on mesangial ECM production. In addition, associated metabolic alterations related to hyperglycemia or increased protein intake $(21,60,72)$ may further facilitate the abnormally increased formation and deposition of ECM, and mesangial expansion.

\section{Acknowledgments}

We wish to acknowledge gratefully the help provided by Dr. Sadayoshi Ito in the setting up of the glomerular microperfusion techniques. We thank Greenfield Health Care Systems Corporation for their support in the equipment procurement for the microperfusion laboratory.

The methods for the measurement of extracellular matrix production were developed with the support of National Institutes of Health grant RO1 DK28081.

\section{References}

1. Hostetter, T. H., J. L. Olson, H. G. Rennke, M. A. Venkatachalam, and B. M. Brenner. 1981. Hyperfiltration in remnant nephrons: a potentially adverse response to renal ablation. Am. J. Physiol. 241:F85-F93.

2. Hostetter, T. H., J. L. Troy, and B. M. Brenner. 1981. Glomerular hemodynamics in experimental diabetes mellitus. Kidney Int. 19:410-415.

3. Zatz, R., T. W. Meyer, H. G. Rennke, and B. M. Brenner. 1985. Predominance of hemodynamic rather than metabolic factors in the pathogenesis of diabetic nephropathy. Proc. Natl. Acad. Sci. USA. 82:5963-5967.

4. Dworkin, L. D., and H. D. Feiner. 1986. Glomerular injury in uninephrectomized spontaneously hypertensive rats. A consequence of glomerular capillary hypertension. J. Clin. Invest. 77:797-809.

5. Raij, L., S. Aznar, and W. Keane. 1984. Mesangial immune injury, hypertension, and progressive glomerular damage in Dahl rats. Kidney Int. 26:137143.

6. Yoshida, Y., A. Fogo, and I. Ichikawa. 1989. Glomerular hemodynamic changes vs. hypertrophy in experimental glomerular sclerosis. Kidney Int. 35:654-660.

7. Daniels, B. S., and T. H. Hostetter. 1990. Adverse effects of growth in the glomerular microcirculation. Am. J. Physiol. 258:F1409-F1416.

8. MacKay, K., L. J. Striker, J. W. Stauffer, L. Y. Agodoa, and G. E. Striker. 1990. Relationship of glomerular hypertrophy and sclerosis: studies in SV40 transgenic mice. Kidney Int. 37:741-748.

9. Fries, J. W. U., D. J. Sandstrom, T. W. Meyer, and H. G. Rennke. 1989. Glomerular hypertrophy and epithelial cell injury modulate progressive glomerulosclerosis in the rat. Lab. Invest. 60:205-218.

10. Mauer, S. M., M. W. Steffes, S. Aznar, and D. M. Brown. 1989. Effects of dietary protein content in streptozotocin-diabetic rats. Kidney Int. 35:48-59.

11. Doi, T., L. J. Striker, C. Quaife, F. G. Conti, R. Palmiter, R. Behringer, R. Brinster, and G. E. Striker. 1988. Progressive glomerulosclerosis develops in transgenic mice chronically expressing growth hormone and growth hormone releasing factor but not in those expressing insulinlike growth factor-1. Am. J. Pathol. 131:398-403.

12. El Nahas, A. M., A. H. Bassett, G. H. Cope, and J. E. Le Carpentier. 1991. Role of growth hormone in the development of experimental renal scarring. Kidney Int. 40:29-34.

13. Border, W. A., S. Okuda, L. R. Languino, and E. Ruoslahti. 1990. Transforming growth factor- $\beta$ regulates production of proteoglycans by mesangial cells. Kidney Int. 37:689-695.

14. Miller, P. L., J. W. Scholey, H. G. Rennke, and T. W. Meyer. 1990. Glomerular hypertrophy aggravates epithelial cell injury in nephrotic rats. $J$. Clin. Invest. 85:1119-1126.

15. Miller, P. L., H. G. Rennke, and T. W. Meyer. 1991. Glomerular hypertrophy accelerates hypertensive glomerular injury in rats. Am. J. Physiol. 261:F459-465.

16. Osgood, R. W., M. Patton, M. J. Hanley, M. Venkatachalam, H. J. Reineck, and J. H. Stein. 1983. In vitro perfusion of the isolated dog glomerulus. Am. J. Physiol. 244:F349-F354.

17. Jensen, E. B., H. J. G. Gundersen, and R. Osterby. 1979. Determination of membrane thickness distribution from orthogonal intercepts. J. Microsc. (Oxf.). 115:19-33.

18. Cortes, P., X. Zhao, J. Atherton, and F. Dumler. 1991. Age-related changes in glomerular size and collagen content in rat and human. J. Am. Soc. Nephrol. 2:1716-1725.

19. Dumler, F., and P. Cortes. 1988. Uracil ribonucleotide metabolism in rat and human glomerular epithelial and mesangial cells. Am. J. Physiol. 255:C712C718.

20. Sterzel, R. B., D. H. Lovett, H. G. Foellmer, M. Perfetto, D. Biemesderfer, and M. Kashgarian. 1986. Mesangial cell hillocks. Nodular foci of exaggerated growth of cells and matrix in prolonged culture. Am. J. Pathol. 125:130-140.

21. Ayo, S. H., R. A. Radnik, W. F. Glass II, J. A. Garoni, E. R. Rampt, D. R. Appling, and J. I. Kreisberg. 1990. Increased extracellular matrix synthesis and mRNA in mesangial cells grown in high-glucose medium. Am. J. Physiol. 260:F185-F191.

22. Munro, H. N., and A. Fleck. 1966. The determination of nucleic acids. Methods Biochem. Anal. 12:113-176.

23. Varani, J., B. J. Nickoloff, B. L. Riser, R. S. Mitra, and V. M. Dixit. 1988. Thrombospondin-induced adhesion of human keratinocytes. J. Clin. Invest. 81:1537-1544.

24. Negro, A., S. Garbisa, L. Gotte, and M. Spina. 1987. The use of reverse phase high-performance liquid chromatography and precolumn derivatization with dansyl chloride for quantitation of specific amino acids in collagen and elastin. Anal. Biochem. 160:39-46.

25. Parris, N., and D. Gallelli. 1984. Dansylation of amino acids and by-product formation. J. Liq. Chromatogr. 7:917-924.

26. Cortes, P., F. Dumler, K. S. S. Sastry, C. P. Verghese, and N. W. Levin. 1982. Effects of early diabetes on uridine diphosphosugar synthesis in the rat renal cortex. Kidney Int. 21:676-682.

27. Tsanev, R., and G. Markov. 1960. Substances interfering with spectrophotometric estimation of nucleic acids and their elimination by the two-wavelength method. Biochim. Biophys. Acta. 42:442-452.

28. Doi, E. T., D. Shibata, and T. Matoba. 1981. Modified colorimetric ninhydrin method for peptidase assay. Anal. Biochem. 118:173-184.

29. Anderson, S., T. W. Meyer, H. G. Rennke, and B. Brenner. 1985. Control of glomerular hypertension limits glomerular injury in rats with reduced renal mass. J. Clin. Invest. 76:612-619.

30. Olson, J. L., and R. H. Heptinstall. 1988. Nonimmunological mechanisms of glomerular injury. Lab. Invest. 59:564-578.

31. Klahr, S., G. Schereiner, and I. Ichikawa. 1988. The progression of renal disease. N. Engl. J. Med. 318:1657-1666.

32. Anderson, S., T. W. Meyer, H. G. Rennke, and B. Brenner. 1985. Control of glomerular hypertension limits glomerular injury in rats with reduced renal mass. J. Clin. Invest. 76:612-619.

33. Hostetter, T. H., T. W. Meyer, H. G. Rennke, and B. M. Brenner. 1986. Chronic effects of dietary protein in the rat with intact and reduced renal mass. Kidney Int. 30:509-517.

34. Zatz, R., B. R. Dunn, T. W. Meyer, S. Anderson, H. G. Rennke, and B. Brenner. 1986. Prevention of diabetic glomerulopathy by pharmacological amelioration of glomerular capillary hypertension. J. Clin. Invest. 77:1925-1930.

35. Ikoma, M., T. Kawamura, Y. Kakinuma, A. Fogo, and I. Ichicawa. 1991. Cause of variable therapeutic effect of angiotensin converting enzyme inhibitor on glomerular lesions. Kidney Int. 40:195-202.

36. O'Donnel, M. P., B. L. Kasiske, P. G. Schmitz, and W. F. Keane. 1990. High protein intake accelerates glomerulosclerosis independent of effects on glomerular hemodynamics. Kidney Int. 37:1263-1269.

37. Miller, P. L., and T. W. Meyer. 1990. Methods in laboratory investigation. Effects of tissue preparation on glomerular volume and capillary structure in the rat. Lab. Invest. 63:862-866.

38. Kunkel, P. A. 1930. The number and size of the glomeruli in the kidney of several mammals. Bull. Johns Hopkins Hosp. 47:285-291.

39. Nave, C. R., and B. C. Nave. 1980. Physics for the Health Sciences. W. B. Saunders Co., Philadelphia. 111 pp.

40. Kritz, W., M. Elger, K. Lemley, and T. Sakai. 1990. Structure of the glomerular mesangium: a biomechanical interpretation. Kidney Int. 38(Suppl. 30):S2-S9.

41. Singhal, P. C., S. DeCandido, J. A. Satriano, D. Schlondorff, and R. M. Hays. 1989. Atrial natriuretic peptide and nitroprusside cause relaxation of cultured rat mesangial cells. Am. J. Physiol. 257:C86-C93.

42. Martin, G. R., R. Timpl, and K. Kühn. 1988. Basement membrane proteins: molecular structure and function. Adv. Protein Chem. 39:1-50.

43. Savage, C. O. S., C. D. Pusey, M. J. Kershaw, S. J. Cashman, P. Harrison, B. Hartley, D. R. Turner, J. S. Cameron, D. J. Evans, and C. M. Lockwood. 1986. The Goodpasture antigen in Alport's syndrome: studies with a monoclonal antibody. Kidney Int. 30:107-112.

44. Thorner, P., B. Jansen, R. Baumal, V. E. Valli, and A. Goldberger. 1987. Samoyed hereditary glomerulopathy. Immunohistochemical staining of basement membranes of kidney for laminin, collagen type IV, fibronectin, and Goodpasture antigen, and correlation with electron microscopy of glomerular capillary basement membranes. Lab. Invest. 56:435-443. 
45. Le Pape, A., J.-D. Guitton, and J.-P. Muh. 1981. Modification of glomerular basement membrane cross-links in experimental diabetic rats. Biochem. Biophys. Res. Commun. 100:1214-1221.

46. Coperland, K. R., R. W. Yatscoff, J. A. Thliveris, A. Mehta, and B. Penner. 1987. Non-enzymatic glycation and altered renal structure and function in the diabetic rat. Kidney Int. 32:664-670.

47. Kikkawa, R., E. Kitamura, Y. Fujiwara, T. Arimura, M. Haneda, and Y. Shigeta. 1986. Impaired contractile responsiveness of diabetic glomeruli to angiotensin II: a possible indication of mesangial dysfunction in diabetes mellitus. Biochem. Biophys. Res. Commun. 136:1185-1190.

48. Ballermann, B. J., K. L. Skorecki, and B. M. Brenner. 1984. Reduced glomerular angiotensin II receptor density in early untreated diabetes mellitus in the rat. Am. J. Physiol. 247:F110-F116.

49. Falk, R. J., J. I. Scheinman, S. M. Mauer, and A. F. Michael. 1983. Polyantigenic expansion of basement membrane constituents in diabetic nephropathy. Diabetes. 32(Suppl. 2):34-39.

50. Ardaillou, N., G. Bellon, M.-P. Nivez, S. Rakotoarison, and R. Ardaillou. 1989. Quantification of collagen synthesis by cultured human glomerular cells. Biochim. Biophys. Acta. 991:445-452.

51. Ohyama, K., J. M. Seyer, R. Raghow, and A. H. Kang. 1990. Extracellular matrix phenotype of rat mesangial cells in culture. Biosynthesis of collagen types I, III, IV, and V and a low molecular weight collagenous component and their regulation by dexamethasone. J. Lab. Clin. Med. 116:219-227.

52. Ledoux, J. E., L. W. Tucker, A. Del Bo, G. Harshfield, L. Green, W. T. Talman, and D. J. Reis. 1980. A hierarchical organization of blood pressure during natural behaviour in rat and the effects of central catecholamine neurons thereon. Clin. Sci. (Lond.) 59:271s-273s.

53. Pelayo, J., and J. Y. Wescott. 1991. Impaired regulation of glomerular capillary hydrostatic pressure in the rat remnant nephron. J. Clin. Invest. 88:101105.

54. Olson, J. L., S. K. Wilson, and R. H. Heptinstall. 1986. Relation of glomerular injury to preglomerular resistance in experimental hypertension. Kidney Int. 29:847-857.

55. Bidani, A. K., M. M. Schwartz, and E. J. Lewis. 1987. Renal autoregulation and vulnerability to hypertensive injury in remnant kidney. Am. J. Physiol. 252:F1003-F1010.

56. Iversen, B. M., J. Ofstad. 1988. Loss of renal blood flow autoregulation in chronic glomerulonephritic rats. Am. J. Physiol. 254:F284-F290.

57. Hashimoto, Y., T. Ideura, A. Yoshimura, S. Koshikawa. 1989. Autoregulation of renal blood flow in streptozotocin-induced diabetic rats. Diabetes. 38:1109-1113.
58. Drumond, M. C., and W. M. Deen. 1991. Analysis of pulsatile pressures and flows in glomerular filtration. Am. J. Physiol. 261:F409-F419.

59. Ruoslahti, E. 1991. Integrins. J. Clin. Invest. 87:1-5.

60. Sumpio, B. E., A. J. Banes, W. G. Link, and G. Johnson. 1988. Enhanced collagen production by smooth muscle cells during repetitive mechanical stretching. Arch. Surg. 123:1233-1236.

61. Kollros, P. R., S. R. Bates, M. B. Mathews, A. L. Horwitz, and S. Glagov. 1987. Cyclic AMP inhibits increased collagen production by cyclically stretched smooth muscle cells. Lab. Invest. 56:410-417.

62. Filipovic, D., and H. Sackin. 1991. A calcium-permeable stretch-activated cation channel in renal proximal tubule. Am. J. Physiol. 260:F119-F129.

63. Haneda, M., R. Kikkawa, N. Horide, M. Togawa, D. Koya, N. Kajiwara, A. Ooshima, and Y. Shigeta. 1991. Glucose enhances type IV collagen production in cultured rat glomerular cells. Diabetologia. 34:198-200.

64. Holderbaum, D., and L. A. Ehrhart. 1984. Modulation of type I and II procollagen synthesis at various stages of arterial smooth muscle cell growth in vitro. Exp. Cell Res. 153:16-24.

65. Wolthius, A., A. Boes, H. P. Rodemann, and J. Grond. 1992. Vasoactive agents affect growth and protein synthesis of cultured rat mesangial cells. Kidney Int. 41:124-131.

66. Pesce, C. M., L. J. Striker, E. Peten, S. J. Elliot, and G. E. Striker. 1991. Glomerulosclerosis at both early and late stages is associated with increased cell turnover in mice transgenic for growth hormone. Lab. Invest. 65:601-605.

67. Olivetti, G., P. Anversa, W. Rigamonti, L. Vitali-Mazza, and A. V. Loud. 1977. Morphometry of the renal corpuscle during normal postnatal growth and compensatory hypertrophy. J. Cell Biol. 75:573-585.

68. Grond, J., J. Y. B. Beukens, M. S. Schilthuis, J. J. Weening, and J. D. Elema. 1986. Analysis of renal structural and functional features in two rat strains with a different susceptibility to glomerular sclerosis. Lab. Invest. 54:77-83.

69. Oterby, R., and H. J. G. Gundersen. 1980. Fast accumulation of basement membrane material and the rate of morphological changes in acute experimental diabetic glomerular hypertrophy. Diabetologia. 18:493-500.

70. Cortes, P., F. Dumler, K. K. Venkatachalam, J. Goldman, K. S. S. Sastry, H. Venkatachalam, J. Bernstein, and N. W. Levin. 1981. Alterations in glomerular RNA in diabetic rats: roles of glucagon and insulin. Kidney Int. 20:491-499.

71. Jakobsson, B., S.-O. Bohman, B. Sundelin, and A. Aperia. 1988. Mitotic response to high protein intake in different renal cell types in weanling rats. Kidney Int. 33:662-666.

72. Cortes, P., F. Dumler, D. L. Paielli, and N. W. Levin. 1988. Glomerular uracil nucleotide synthesis: effects of diabetes and protein intake. Am. J. Physiol. 255:F647-F655. 